Recepción: 23/ 04/ 2017

Aceptación: 27 / 05/ 2017

Publicación: 01/ 09/2017

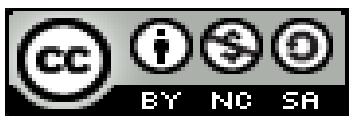

Ciencias de la educación

\title{
El trabajo social en el ámbito educativo y risuka
}

\author{
Social work in the educational field and risuka
}

\section{Trabalho social no campo educacional e risuka}

\author{
Aída P. Haro-Lara I \\ ap.haro@uta.edu.ec \\ Malena K. Quiroga-López II \\ malenakquirogal@uta.edu.ec \\ Segundo Ramiro Tite III \\ jrtitelegal@yahoo.es \\ Daniela F. Caicedo-Vargas IV \\ dafer.21@hotmail.com
}

\section{Correspondencia: ap.haro@uta.edu.ec}

I Magister en Trabajo Social Familiar, Licenciado en Trabajo Social, Abogada, Universidad Nacional de Loja.

II Magister en Mediación Arbitraje y Solución de Conflictos, Magister en Desarrollo Humano, Especialista en Gestión Social, Licenciada en Trabajo Social, Universidad Católica del Ecuador.

III Magister en Derecho Procesal mención Derecho Penal, Abogado de los Tribunales de Justicia de la Republica, Universidad Técnica de Ambato, Ambato, Ecuador.

IV Licenciada en Trabajo Social, Docente de la Universidad Técnica de Ambato, Ambato, Ecuador. 


\title{
Resumen
}

En el actual periodo de tiempo, la juventud y en especial los adolescentes están inmersos en dificultades reflejadas en sus contextos próximos. Dentro de la convivencia familiar es común ver cómo se ha ido deteriorando la familia por problemas de empleabilidad, comunicación inadecuada, nuevos patrones comportamentales, entre otros; generando una permanente tensión. Cabe mencionar que, el espacio físico pierde su categoría de hogar para convertirse en un epicentro poco habitable por la violencia reflejada; puesto que los hijos, en especial los adolescentes tratan de buscar escape y refugio en drogas, alcohol o manifestaciones de actitudes con desacuerdos mediante autolesiones como el Cutting. La investigación responde como objetivo general: Determinar la influencia que tiene la aplicación de estrategias de intervención desde el trabajo social frente al hábito relacionado con el Cutting de los estudiantes. Para ello mediante un enfoque cuali-cuantitativo, son encuestados ciento sesenta estudiantes de octavo, noveno y décimo año de educación básica.

Palabras clave: estrategias de intervención; trabajo social; cutting; familia.

\begin{abstract}
In the current period of time, youth and especially adolescents are immersed in difficulties reflected in their immediate contexts. Within family coexistence it is common to see how the family has deteriorated due to employability problems, inadequate communication, new behavioral patterns, among others; generating a permanent tension. It is worth mentioning that, the physical space loses its category of home to become an epicenter not habitable due to the reflected violence; since the children, especially the adolescents try to find escape and refuge in drugs, alcohol or manifestations of attitudes with disagreements through self-harm such as Cutting. The research responds as a general objective: Determine the influence of the application of intervention strategies from social work against the habit related to the Cutting of students. For this purpose, through a qualitative-quantitative approach, one hundred and sixty students from the eighth, ninth and tenth years of basic education are surveyed.
\end{abstract}

Keywords: intervention strategies; social work; cutting; family. 


\section{Resumo}

No período de tempo atual, os jovens e especialmente os adolescentes estão imersos em dificuldades refletidas em seus contextos imediatos. Dentro da coexistência familiar, é comum ver como a família se deteriorou devido a problemas de empregabilidade, comunicação inadequada, novos padrões comportamentais, entre outros; gerando uma tensão permanente. Vale ressaltar que, o espaço físico perde sua categoria de lar para se tornar um epicentro não habitável devido à violência refletida; uma vez que as crianças, especialmente os adolescentes, tentam encontrar fuga e refúgio em drogas, álcool ou manifestações de atitudes com desentendimentos por autojudicação, como Cutting. A pesquisa responde como um objetivo geral: determinar a influência da aplicação das estratégias de intervenção do trabalho social em relação ao hábito relacionado ao corte dos alunos. Para este propósito, através de uma abordagem qualitativaquantitativa, são pesquisados cento e sessenta alunos do oitavo, nono e décimo anos de educação básica.

Palavras chave: estratégias de intervenção; trabalho social; corte; família.

\section{Introducción}

En la época actual la juventud y en especial los adolescentes, están inmersos en dificultades reflejadas en sus contextos próximos. Dentro de la convivencia familiar es común ver cómo se va deteriorando la familia por problemas de empleabilidad, comunicación inadecuada, nuevos patrones comportamentales, entre otros; generando así una permanente tensión. El espacio físico pierde su categoría de hogar para convertirse en un epicentro poco habitable por la violencia reflejada. Los hijos, especialmente los adolescentes, quienes tratan de buscar escape refugiándose en drogas o alcohol, así como el manifestar sus desacuerdos mediante autolesiones como el Cutting.

Para Cruz (2016), el Cutting se define como "la acción lesiva intencional que una persona lleva a cabo en sí misma, produciéndose con ello un daño corporal de baja letalidad, de una naturaleza socialmente inaceptable; se trata de una acción deliberada y comúnmente repetitiva", la cual puede implementarse de forma crónica como una forma de reducir el estrés o malestar emocional, es decir un mecanismo de enfrentamiento autodestructivo. 
La Universidad Tecnológica Metropolitana del Estado de Chile (2012), afirma que el medio escolar es el primer entorno donde se pueden detectar problemas familiares y sociales, considerando éste entorno como uno de los pilares de prevención ya que identifica posibles conductas inadecuadas antes que otras instituciones de forma globalizada y facilitando una intervención temprana.

La literatura expone sobre la práctica de este hábito en el cual, algunos niños desde muy pequeños se dañan a sí mismo, y ciertos adultos también, personas con edades "comprendida entre los veinticinco años, ya que las tasas de autoagresión son mucho más altas entre los jóvenes; además que uno de cada cinco jóvenes entra en las tasas de auto daño, siendo Reino Unido el lugar con mayor índice en Europa" (Brophy \& Holmstrom, 2006).

Uno de los países latinoamericanos con mayores índices de práctica de Cutting (autolaceraciones), es México por lo que el Congreso del Estado de Chihuahua aprobó de manera unánime la propuesta del grupo parlamentario del partido Nueva Alianza, para que se atienda como un problema de salud pública (periódico digital Chihuahuanoticias, 2012).

En Ecuador, según lo emitido por la Dra. Jackeline Lamboglia -Jefe del área vida que pertenece al Instituto de Neurociencias- a la junta de beneficencia "se indica que, durante el 2016, de cada diez adolescentes que ingresan en el área de Vida del instituto, cinco presentan conducta de Cutting, en su mayoría mujeres y en el transcurso del 2015 el área Vida recibió a cincuenta y cinco pacientes de los cuales treinta y cinco presentaban autolesiones". (Junta de Beneficencia de Guayaquil, 2016).

A nivel de intervención profesional, el trabajo social en el área educativa del cantón Ambato (Ecuador) responde a planificaciones impuestas por un modelo estatal indiferente a las realidades concretas de cada instancia como son: pertenencia, origen, situación socio familiar, así como el ser parte de una institución educativa pública o privada. Los procesos de intervención se generalizan a través del departamento de consejería estudiantil y las mismas no superan lo tradicional, los protocolos son repetitivos y no especializados.

La investigación responde al objetivo general: Determinar la influencia que tiene la aplicación de estrategias de intervención desde el trabajo social frente al hábito relacionado con el Cutting de los estudiantes. 


\section{Metodología}

Este trabajo responde al enfoque cuali-cuantitativo. Son encuestados ciento sesenta estudiantes de octavo, noveno y décimo año de educación básica.

\section{Desarrollo}

El Estado está interesado a través de sus políticas públicas y sociales en generar planes programas y proyectos orientados a la intervención y no a la prevención de problemáticas que aquejan a los adolescentes.

Los resultados de este estudio, permiten dilucidar que no existe una capacitación adecuada y oportuna en temas de interés actual como el cutting, cuyo desconocimiento conlleva a la asimilación de constructos imaginarios o discursivos de este hábito no aceptado socialmente, pero aprobado por los auto agresores como una acción que provoca satisfacción y tranquilidad ante las adversidades suscitadas, especialmente en su entorno familiar.

Al preguntarles que si se han cortado alguna parte del cuerpo de forma intencional el $72 \%$ manifiestan que no lo han hecho, sin embargo, un 28\% sostienen que sí; revelando la existencia de este hábito y la posible propagación del mismo.

Las mujeres son las que hacen más uso de esta práctica, en especial con cortes en las piernas y brazos por la facilidad de poder esconder sus heridas en su uniforme escolar. Ellas sienten la impotencia de reflejar cada una de estas como respuesta a los estímulos negativos de su entorno. Hay temor de ser identificado como un cutter por las represalias institucionales, familiares y por ser sujeto a burlas inadecuadas por parte de la comunidad educativa.

Esta actitud es considerada como normal y de poca importancia, a pesar de que existe un alto porcentaje de adolescentes que buscan satisfacción en cortarse como respuesta a la baja autoestima propiciada por problemas familiares, en especial la violencia interpersonal, auto infringido o suicida y la colectiva.

Los factores explicativos de estos comportamientos pueden ser diversos, sin embargo, según (Montañés, Bartolomé, Montañés, \& Parra, 2008, págs. 393, 401) están relacionados con la vinculación social. 
Por ejemplo, "las relaciones con la familia. Los factores de riesgo y protección no indican causalidad, sino que constituyen condiciones, en este caso del entorno familiar, que predicen una mayor o menor probabilidad de desarrollar un comportamiento, pues la familia ha sido y continúa siendo uno de los contextos socializadores, educativos y transmisor de valores más importantes que tiene no sólo el niño, sino también el adolescente. De ahí la necesidad de mantener la conexión padres - adolescente, esta conexión no puede ser la misma una vez que se inicia el proceso de autonomía del adolescente" (Montañés, Bartolomé, Montañés, \& Parra, 2008, págs. $393,401)$ que se agrede física y emocionalmente para ser tomado en cuenta, llamar la atención sin intención de suicidarse, generando una autodestrucción bio, psico, social; "determinado por sus características biológicas (físicas), pero a su vez su accionar es influenciado por aspectos psicológicos (como deseos, motivaciones e inhibiciones) y por el entorno social (la presión que ejercen otras personas, los condicionamientos legales. Estos tres aspectos (bio, psico y social) no pueden escindirse, sino que constituyen un todo. La conducta del hombre, de hecho, forma una unidad biopsicosocial. Se habla de modelo biopsicosocial con referencia al enfoque que atiende la salud de las personas a partir de la integración de los factores biológicos, psicológicos y sociales. Este modelo entiende que el bienestar del hombre depende de las tres dimensiones: no alcanza con que el individuo esté sano físicamente" (Pérez Porto, 2016).

El tipo de objetos que usan para cortarse, es el estilete por ser un útil escolar, la Gillette por su presentación y fácil acceso al contrario de la navaja o vidrios. Cortarse es sinónimo de satisfacción.

En palabras de una de las estudiantes entrevistadas:

Siento satisfacción, porque cuando me corto me siento mejor, me siento libre y me desahogo.

Me cortaba porque me sentía sola, pese a que vivo con mis padres y hermanos siento que no me toman en cuenta, siento que no tengo interés de cómo estoy como les dan a mis hermanos.

Me cortaba para desahogarme, siempre lo hacía a escondidas de mis familiares, pero cuando me vieron las marcas dijeron que solo lo hacía por llamar la atención, pero en realidad era porque me sentía sola y muchas veces lo hice con la intención de quitarme la vida. 
Lo hacía siempre que tenía problemas en el colegio o en mi casa, por lo general cada semana, las veces que me iba mal, por ejemplo, en el colegio los profesores me decían que yo nunca voy a cambiar que siempre voy a ser una mala influencia, son injustos y en mi casa yo no importo.

Me he sentido discriminada por parte de mis compañeros y profesores ya que me han visto las marcas o les han contado y cuando pido permiso para ir al baño se burlan delante de todos y me lo niegan porque dicen que me he de ir a cortar, minimizando mis problemas.

Ya no he vuelto a cortarme frecuentemente porque veía que las personas me miraban raro y ya no quería q me vieran así, sin embargo, en ocasiones lo hago.

De mi curso conozco de un chico que se corta y de otros cursos conozco algunos, no creo que el DECE sepa que ellos se cortan porque no existe la confianza para hacerlo, en mi caso en particular se enteraron porque una compañera acudió a decirles.

Los profesionales del DECE sí me han brindado apoyo, pero si en algo he logrado salir, no ha sido por ellos sino por terceras personas, ya que cuando acudía al DECE sentía que se cansaban de escucharme y me hacían sentir como si fuera un caso perdido y pararon con las intervenciones.

No siempre me he sentido a gusto en las intervenciones de trabajo social, porque siento que comienzan a valorar siempre mis aspectos negativos y reiterar lo malo que hago, no existe confidencialidad de lo que hablamos pues inmediatamente otras personas lo saben además son repetitivas siempre se habla de lo mismo y es aburrido.

Una guía profesional siempre es necesaria pero no en las condiciones como las que se ha estado dando, porque en un inicio me sentí apoyada sin embargo con el tiempo ya no, además por más que lo quiera dejar, los problemas persisten y hacen que se corten.

Desde que yo estoy en el colegio no hemos recibido talleres, algunos profesores han realizado encuestas sobre Cutting, pero nada más.

Considero que cortarse es una forma de auto agresión porque lastimas tu cuerpo, en un momento si te desahoga, pero cuando te das cuenta te quedan cicatrices y cuando las veo recuerdo todo lo que pasé en esos momentos y me arrepiento de haberme cortado, el cutting es un problema que debe atenderse porque no es un juego, en esos momentos uno no mide el riesgo. 
Es notorio que la intervención inadecuada y el limitado uso de estrategias por parte del trabajo social en el área educativa propicia la proliferación de la práctica de la Risuka.

Cuando los procesos de intervención no son adecuados, carecen de fundamentación teórica y se alejan de la practicidad contribuyen a la injustica social donde son notorias las manifestaciones de rebeldía y reconocimiento como el cutting.

Responsabilizar a la sociedad o a la familia del aparecimiento de esta práctica simplemente aleja de la intervención profesional a través de la categorización de patrones de responsabilidad como es el entorno familiar.

\section{Conclusión}

El aparecimiento del hábito de cutting generalmente se debe a dificultades suscitadas dentro del sistema familiar, tales como: baja autoestima, abusos, maltratos; con el objetivo de llamar la atención, lo cual evidencia una desatención e indiferencia por parte de los padres de familia

No existe la aplicación de estrategias en intervención de modelos, métodos o protocolos adecuados, orientados a la prevención del hábito de cutting desde la perspectiva de trabajo social. Un porcentaje considerable de los estudiantes encuestados indicaron que no han recibido una educación como charlas o talleres, dando lugar al aparecimiento de imaginarios o constructos discursivos por los estudiantes con respecto a dicho problema, por lo que tomando el axioma de la hipótesis, las estrategias de intervención desde trabajo social son un factor determinante frente al cutting en los estudiantes de nivel básico.

En los procesos de intervención de trabajo social, debe considerarse la triada educativa, alumnos, padres de familia y docentes con la finalidad que se involucren, integren y comprometan con el proceso de formación para establecer un equilibrio en el desarrollo de los estudiantes y afianzar lazos familiares y por ende la convivencia educativa.

La necesidad de generar una guía metodológica de intervención desde la perspectiva de trabajo social frente al cutting con enfoque holístico, sistémico y por procesos en prevención, detección, intervención y evaluación para los estudiantes de educación básica. 


\section{Referencias Bibliográficas}

Brophy, M. \&. \& Holmstrom, R. (2006). Informe de la investigación nacional sobre el daño propio entre los jóvenes: realidad o ficción. Londres, Inglaterra: Fundación salud mental

Cruz, R. (14 de octubre de 2016). es.scribd.com. obtenido de autolesión: https://es.scribd.com/document/327606479/Definicion-de-autolesión

Junta de Beneficencia de Guayaquil. (24 de febrero de 2016). Junta de beneficencia.org. Obtenido de cada 10 jóvenes ingresados en el Instituto de neurociencias, 5 presentan síndrome de Cutting: https://www.juntadebeneficencia.org.ec/es/prensa/60-boletines-de-prensa/2912-de cada10-jovenes-ingresados-en-el-instituto-de-neurociencias-5-presentan-sindrome-de-cutting Montañés, M., Bartolomé, R., Montañés, J., \& Parra, M. (2008). Influencia del contexto familiar en las conductas adolescentes. Revista de la facultad de educación de albacete, 393-401. Obtenido de influencia del contexto familiar en las conductas adolescentes

Pérez Porto, J. (8 de agosto de 2016). Definición. Edu. Obtenido de http://definicion.de/biopsicosocial/

Periódico digital Chihuahuanoticias. (02 de abril de 2012). Chihuahuanoticias. Obtenido de deben gobiernos erradicar el "cutting" en infantes y adolescentes: Congreso: http://chihuahuanoticias.com/?p=2003

Universidad Tecnológica Metropolitana del Estado de Chile. (2012). Trabajo social y Educación formal e informal. Revista cuaderno de trabajo social N 5 , 14-15 